\title{
Concept Design for Emergency Closure System for Inland Navigation Structures
}

\section{US Army Corps of Engineers}

by John E. Hite, Jr.

PURPOSE: Emergency closures systems are needed at U.S. Army Corps of Engineers navigation projects to reduce damages and economical impacts associated with uncontrolled flow through the project due to failure of a lock or a dam gate. The most likely cause of failure is a navigation accident although an equipment malfunction or an act of terrorism can also result in failure. This Coastal and Hydraulics Engineering Technical Note (CHETN) provides information and input from Corps field personnel in describing the features considered necessary for a functional emergency closure system.

RECENT TOW/BARGE ACCIDENTS: In recent years, a number of Corps navigation projects have experienced closures in order to repair damaged gates or malfunctioning equipment. Navigation accidents have occurred on many of the inland waterways that resulted in failed gates and disruption to normal operations. Figure 1 shows barges wrapped around a pier at the Belleville project on the Ohio River during the high-water conditions in January 2005. The spillway gates were inoperable due to the interference from the barges and loss of pool occurred. Significant impacts to the navigation industry and normal operations were experienced.

Figure 2 is another example of a navigation accident that occurred at Lock and Dam No. 2 on the Red River, LA, in December 2004. Figure 3 shows a schematic of a navigation accident at the Montgomery Lock and Dam, PA, project on the Ohio River in January 2005, where loss of life occurred. According to a newspaper article in the Pittsburgh, PA Post-Gazette, a strong current caused the front two barges in a six-barge tow to break loose and start floating toward the dam. The towboat untied from the other four barges in the upper lock approach and tried to stop the barges before they reached the dam. The current was too strong and the towboat and three barges went through the dam and sank. The other three barges were pinned against the dam. U.S. Coast Guard Commander Wyman Briggs, captain of the port near the accident, reported that 42 incidents involving 186 barges had occurred in this area in the last 6 years. Strong current due to high water was considered responsible for 75 percent of these incidents. These recent accidents demonstrate the need for every navigation project to possess the capability for emergency closures that will bring the project back under control. Also, it is important for the project to have capability for rapid salvage to remove barges and/or vessels although this topic is not addressed in this CHETN.

Accidents can also occur when typical operations are not possible due to maintenance or malfunctions. Accidental rapid lock valve operations or faulty mooring lines can result in the tow inside the lock chamber moving downstream quicker than expected. The following excerpt was taken from the Waterways Journal dated 27 November 2000 and concerns the McAlpine lock on the Ohio River. 
ERDC/CHL CHETN-IV-70

May 2008

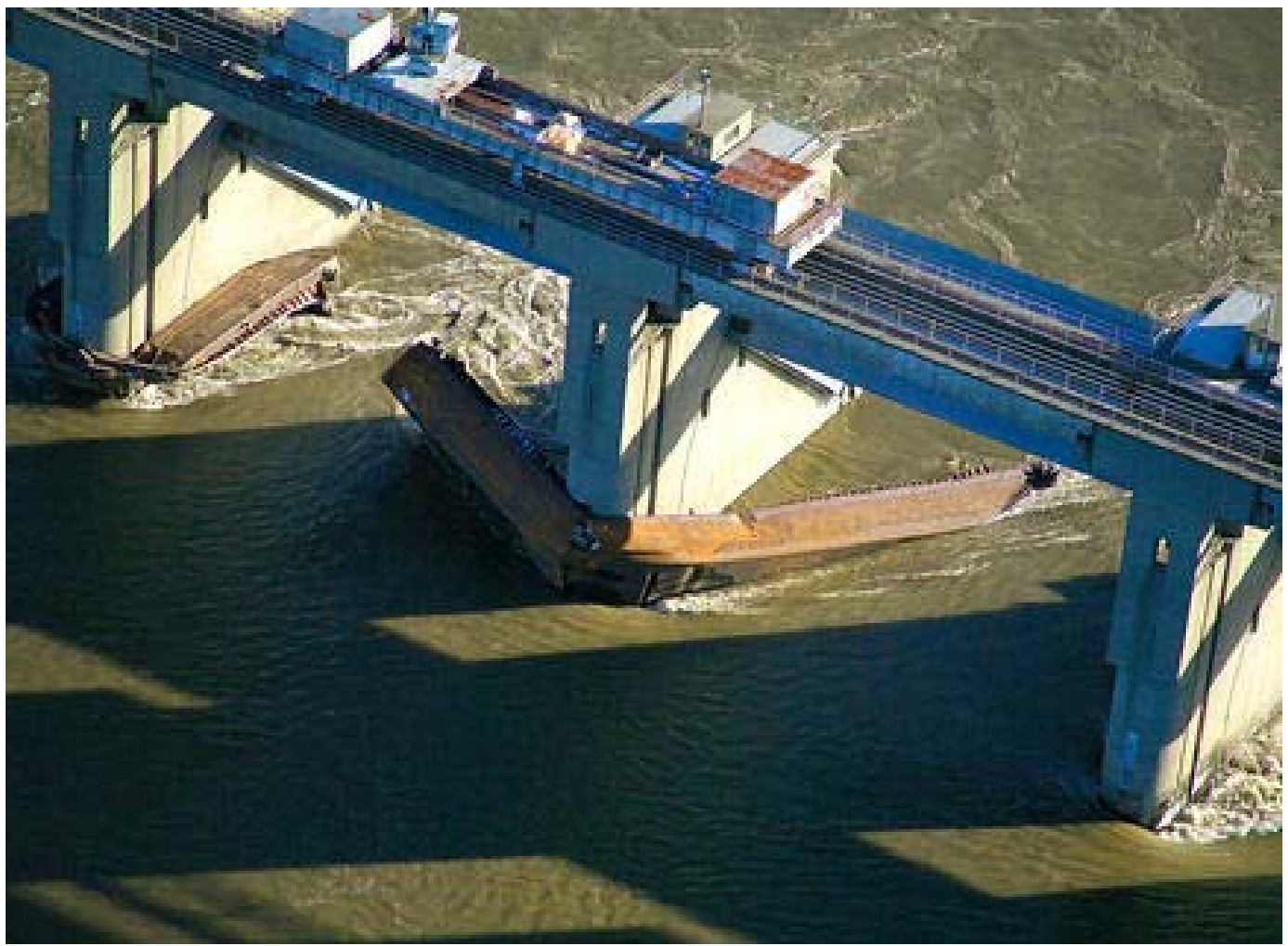

Figure 1. Barge accident at Belleville Dam, Ohio River, Ohio/West Virginia.

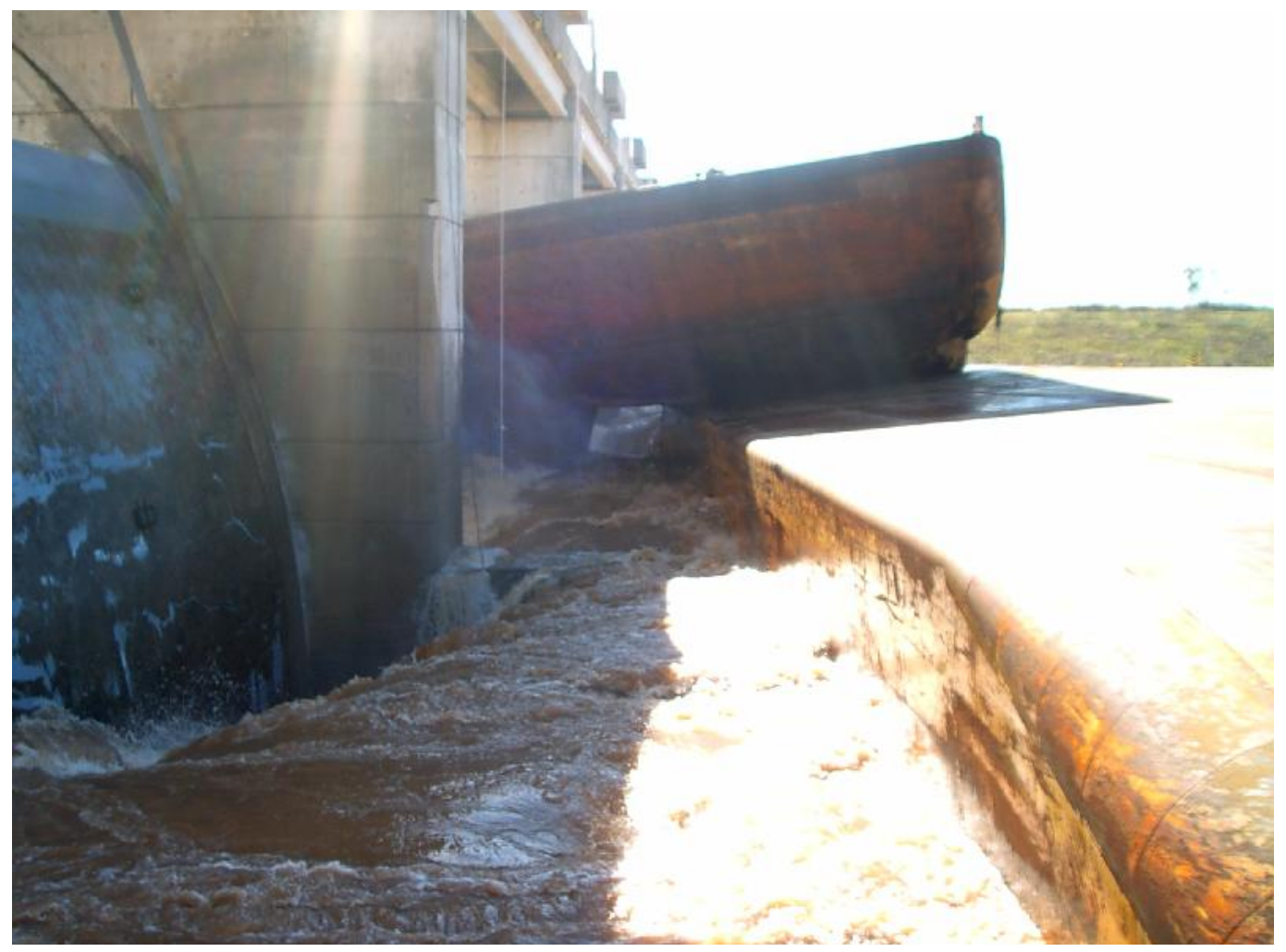

Figure 2. Barge accident at Lock and Dam No. 2, Red River, LA. 


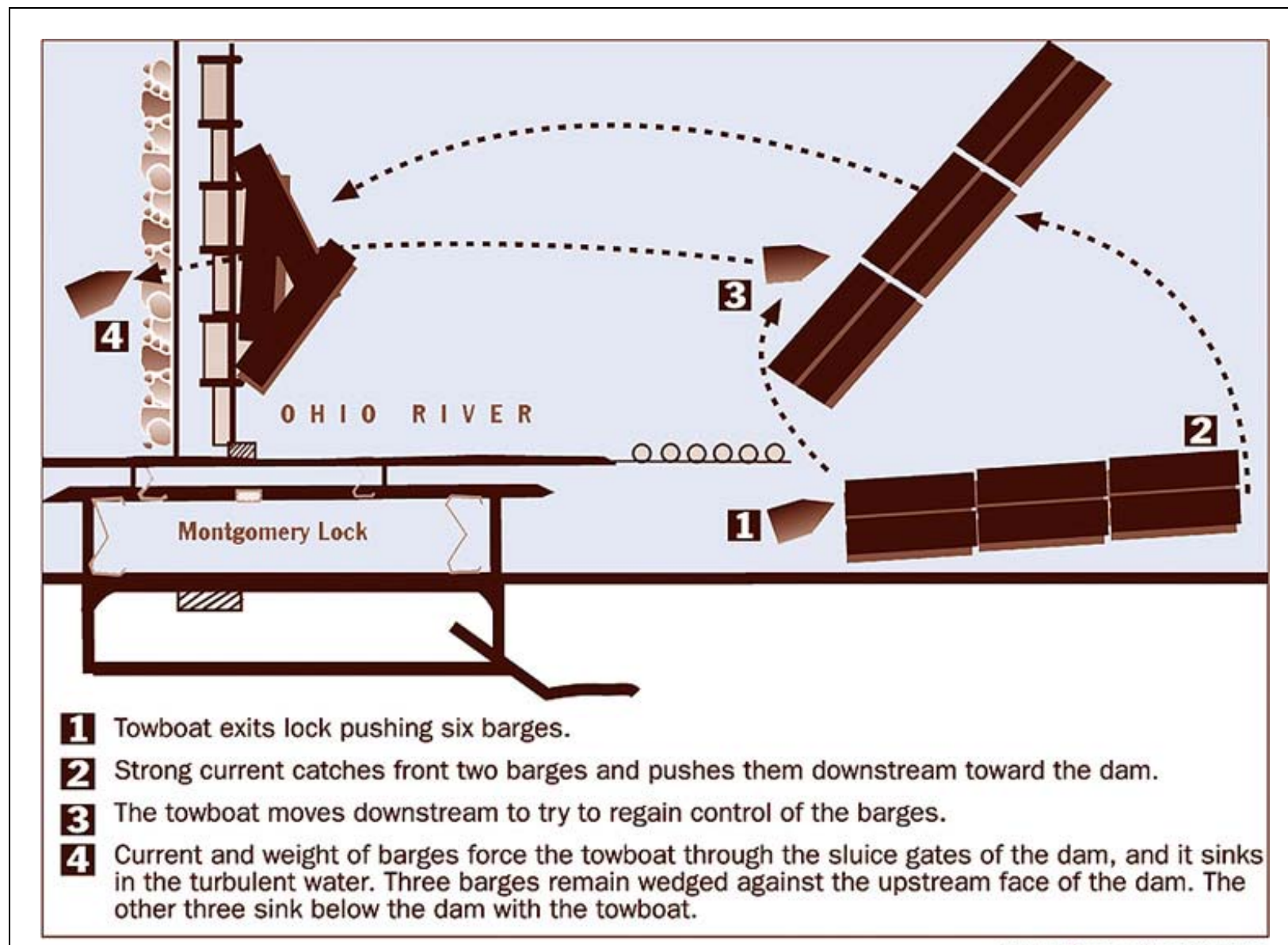

Cathy Tigano/Post-Gazette

Figure 3. Schematic of barge accident at Montgomery Lock and Dam, PA, Ohio River.

"Upbound tows at the lock have reported experiencing a severe surge when the pit is being raised. Several tows have reported breaking wires on tow and lock lines while locking, and one tow hit the upper gate November 21.”

CURRENT PRACTICES: Most Corps projects have temporary bulkheads or closure structures for unwatering during maintenance activities. These structures are generally stored onsite or at a central location so they can be used at several projects. Cranes, stiffleg derricks, derrick boats, and divers are used for installation. These structures are generally installed in a static pool. Figure 4 from Headquarters, U.S. Army Corps of Engineers (1995a) shows a bulkhead closure system typically used in a static pool. If this system is used with flowing water, the lowering carriage and bulkheads are lowered slowly down the bulkhead slot and the flowing water does not pass over the bulkheads. Other types of emergency closure bulkheads that stop the flow of water through the lock or dam are available at a few projects. These existing emergency closure structures typically include sectional bulkheads and vertical lift gates (overhead or submerged) which can be installed in flowing water. HQUSACE (1995b) indicates no universally accepted definition of emergency closure exists. The required action is generally understood to be that a closure structure must be rapidly placed in flowing water under head differential. 


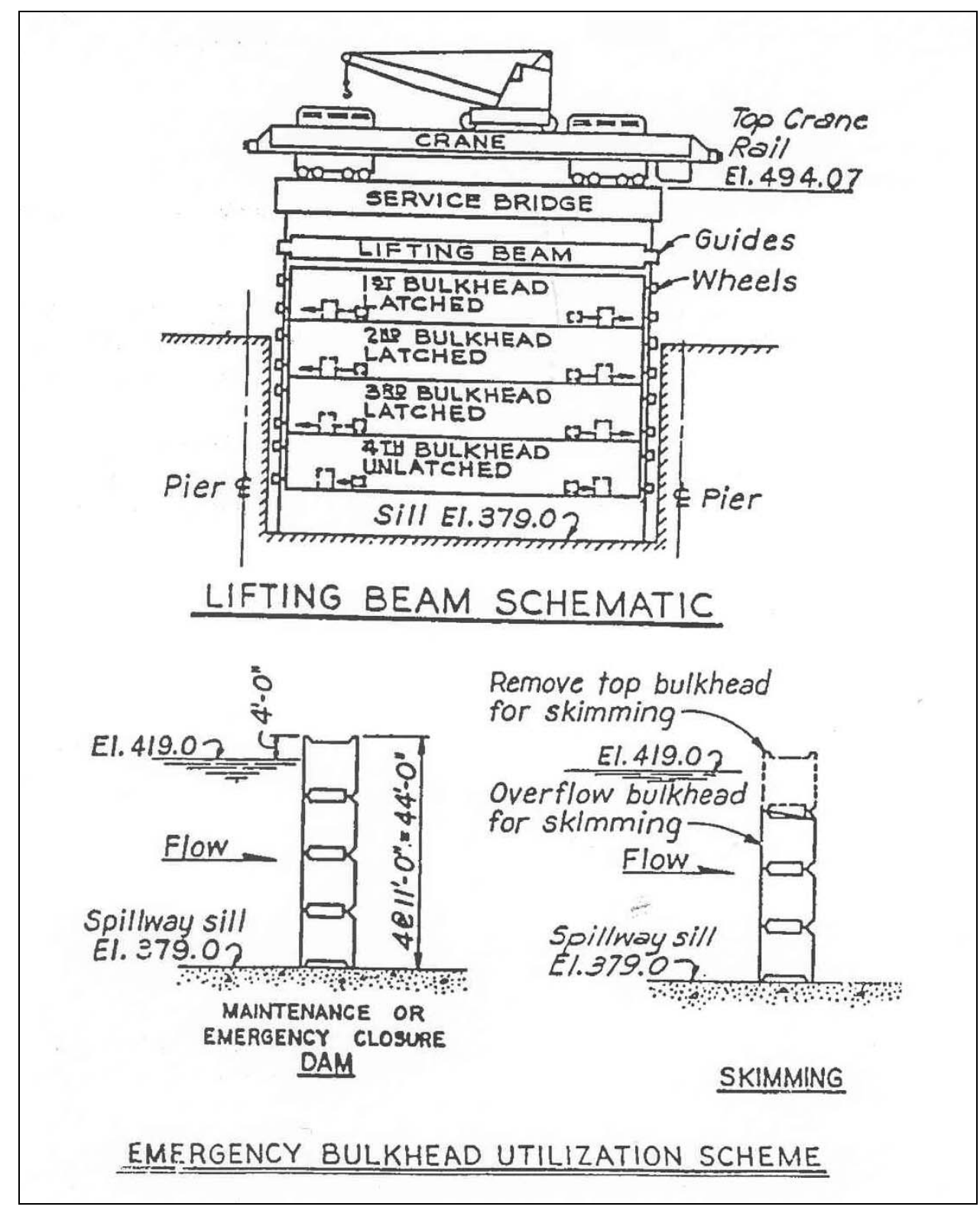

Figure 4. Typical emergency bulkhead closure system from EM 1110-2-2602.

The most common type of emergency closure for locks and spillway gates is a bulkhead consisting of one or more sections and commonly constructed of welded, high strength steel. The choices for new designs are often constrained by operational and economic considerations in addition to function. Economic considerations concern the likelihood of pool loss and its extent of damages and cost incurred. Most bulkhead designs do not permit water flowing over and under the bulkheads during lowering. Some bulkheads are equipped with an overflow plate attached to the top truss and are used for flushing ice and debris.

HQUSACE (1994) provides operation and design guidance for various types of closure devices. Photos of an emergency gate being tested at the McAlpine Lock on the Ohio River are shown in Figure 5. 


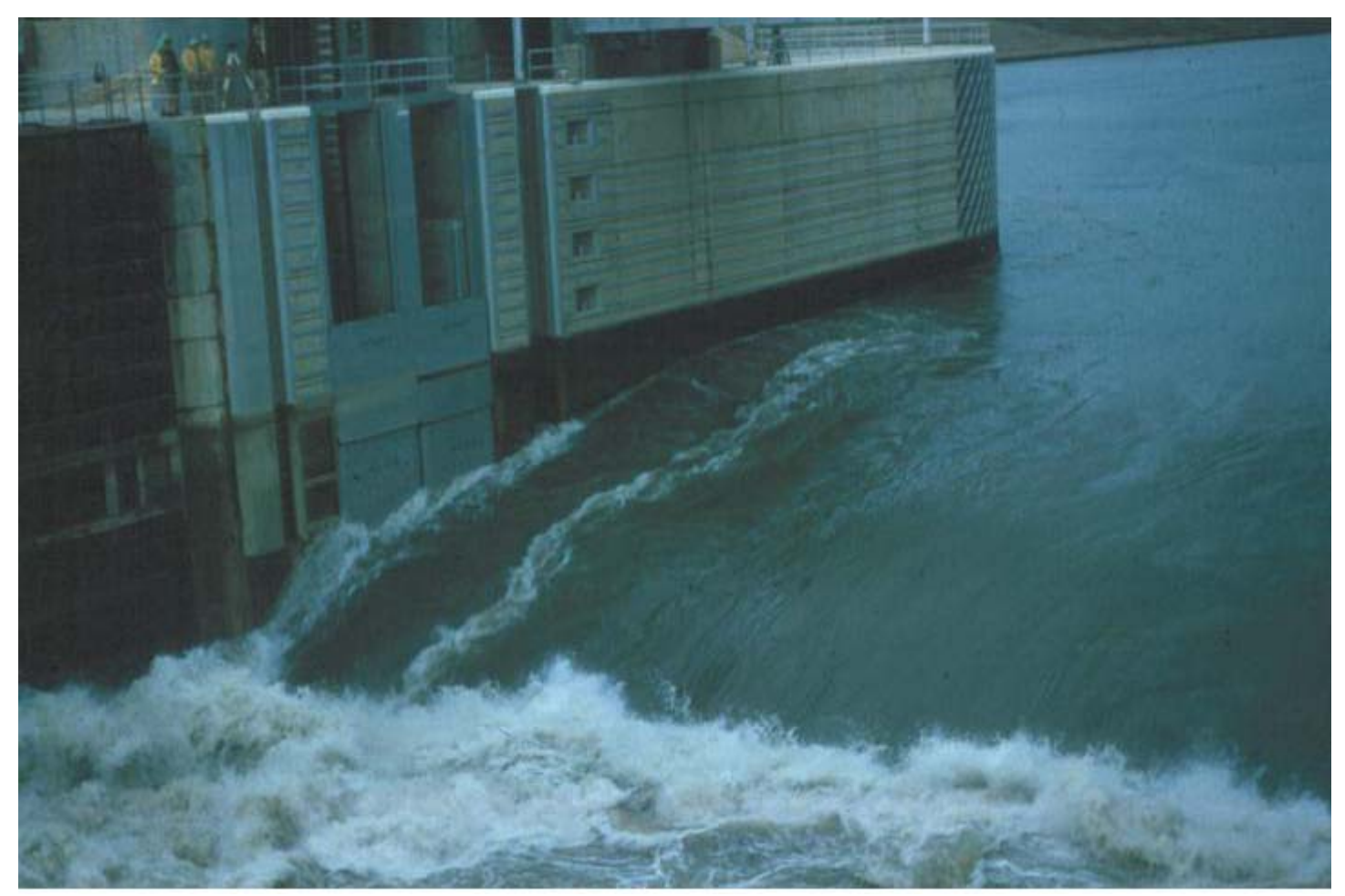

a. Flow conditions before gate is raised.

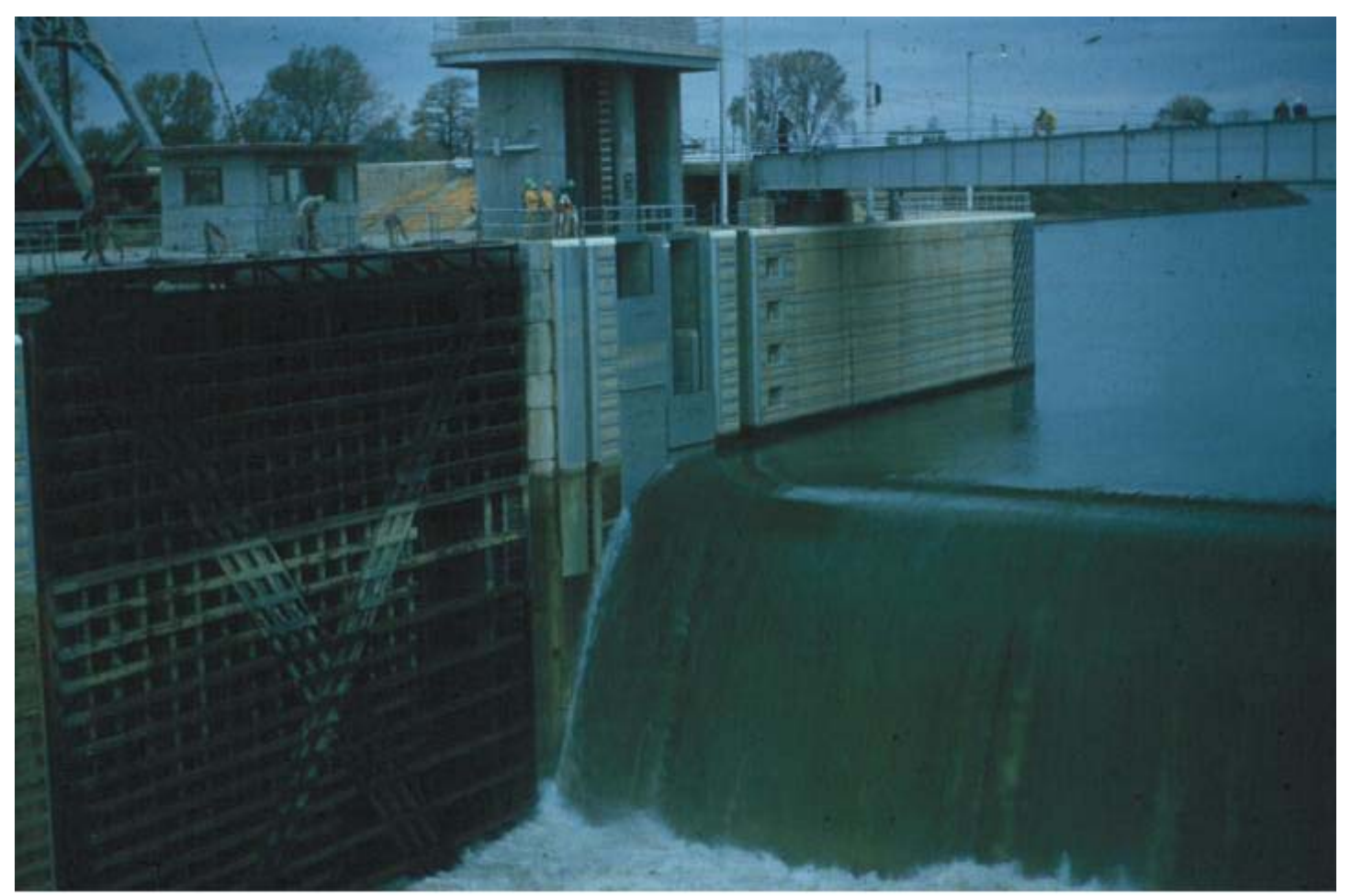

b. Gate approaching upper pool el.

Figure 5. McAlpine Lock emergency closure testing (Continued). 


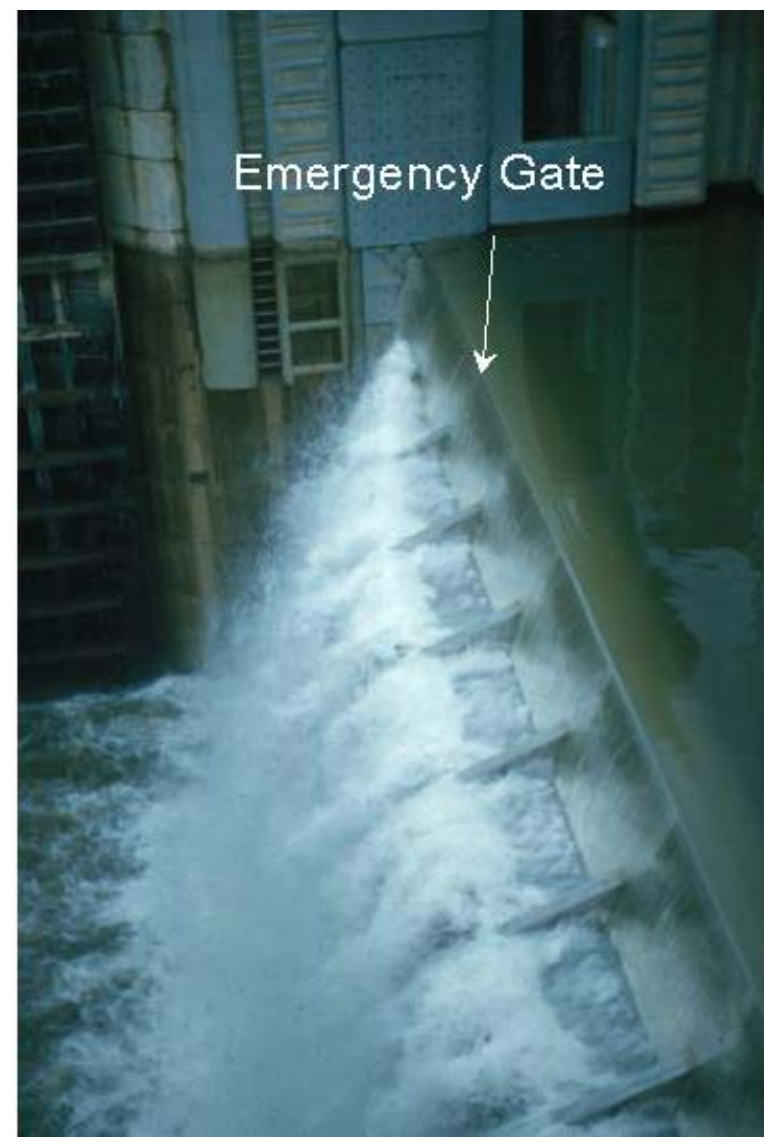

c. Gate near upper pool el.

Figure 5. (Concluded).

An innovative emergency closure system is also needed for projects with existing emergency systems that have experienced operation or maintenance problems or a new innovative system could be deployed faster than the existing system.

DISTRICT COMMENTS: Representatives from several Corps Inland Waterway Districts were contacted to gather information on their needs for an emergency closure system. Pertinent comments from those who responded are provided in the following paragraphs.

\section{Louisville District}

The Louisville District has identified a need for what could be a Division-wide or National resource to close gate bays or chambers under flow. The following ideas were suggested:

- Emergency closure bulkheads should accommodate 110- or 100-ft bays.

- System should consist of short height bulkhead or stop log units that could be transported over the highways.

- Bulkhead units could be stacked into an open frame unit that would be lowered into the water with relatively available floating cranes.

- Filling baskets with rocks could possibly be used to shut off flow similarly to filling gabions under flowing water. 
- Using gate valves in units which could be open when lowered to equalize the water pressure and then closed for dewatering.

- Floated in barriers controlled with cables and wicket gate units.

- A pile of rocks is an option if velocities allow, but the cleanup and recovery time is then made difficult.

\section{New Orleans District}

- For lock systems, standardization of lock geometry could be a simple solution.

- The New Orleans District has three locks within 50 miles of each other, all with different widths.

- Continue to select lock geometry based on economic ratios instead of system pros and cons.

- Standardize bulkhead geometry and weights as much as possible, use the governing load to design bulkheads and gates so they can be used at several structures.

- Fabricating spare parts (including entire gates) would be more economical, interchanging gates, bulkheads and cranes could be done if one looks beyond an isolated structure.

For locks, the New Orleans District uses sector gates when differential heads are less than $12 \mathrm{ft}$. Sector gates can be operated in flowing water. If one set is damaged, the remaining set can still be operated, (closed which is a big plus in New Orleans where the locks are typically part of a flood protection system). New Orleans performed the following analysis to compare a truss bulkhead versus a tension bulkhead (shown in Figure 6). The analysis uses Port Allen Lock bottom bulkhead and compares it to a semicircular thin wall gate section of the same span, material and loading (Table 1).

The tension gate (Figure 6) is much lighter and would be advantageous for using available project equipment to deploy. The end attachments may need some type of support if the unit is used between walls. Existing bulkhead slots could possibly be used for the reaction ends.

\section{St. Louis District}

- Emergency bulkheads are located on the upstream end of the locks.

- Same bulkheads are used for the locks as for the tainter gate bays.

- Bulkheads are stored on dogging devices along the top of the service bridge, over the tainter gate bays where they will not interfere with lock traffic.

- Placed using a permanent 1,600-ton crane which rides on rails on the top of the dam service bridge.

- Possibly can be set in a couple of hours.

- Takes four bulkheads to stop log a gate bay or one of the lock chambers.

- Maintenance bulkheads on the downstream side of each tainter gate bay or lock chamber must be set with floating plant.

The possible use of some type of framework that could be lowered into the water and then filled with some type of impervious material that would shut the flow off was also mentioned. 


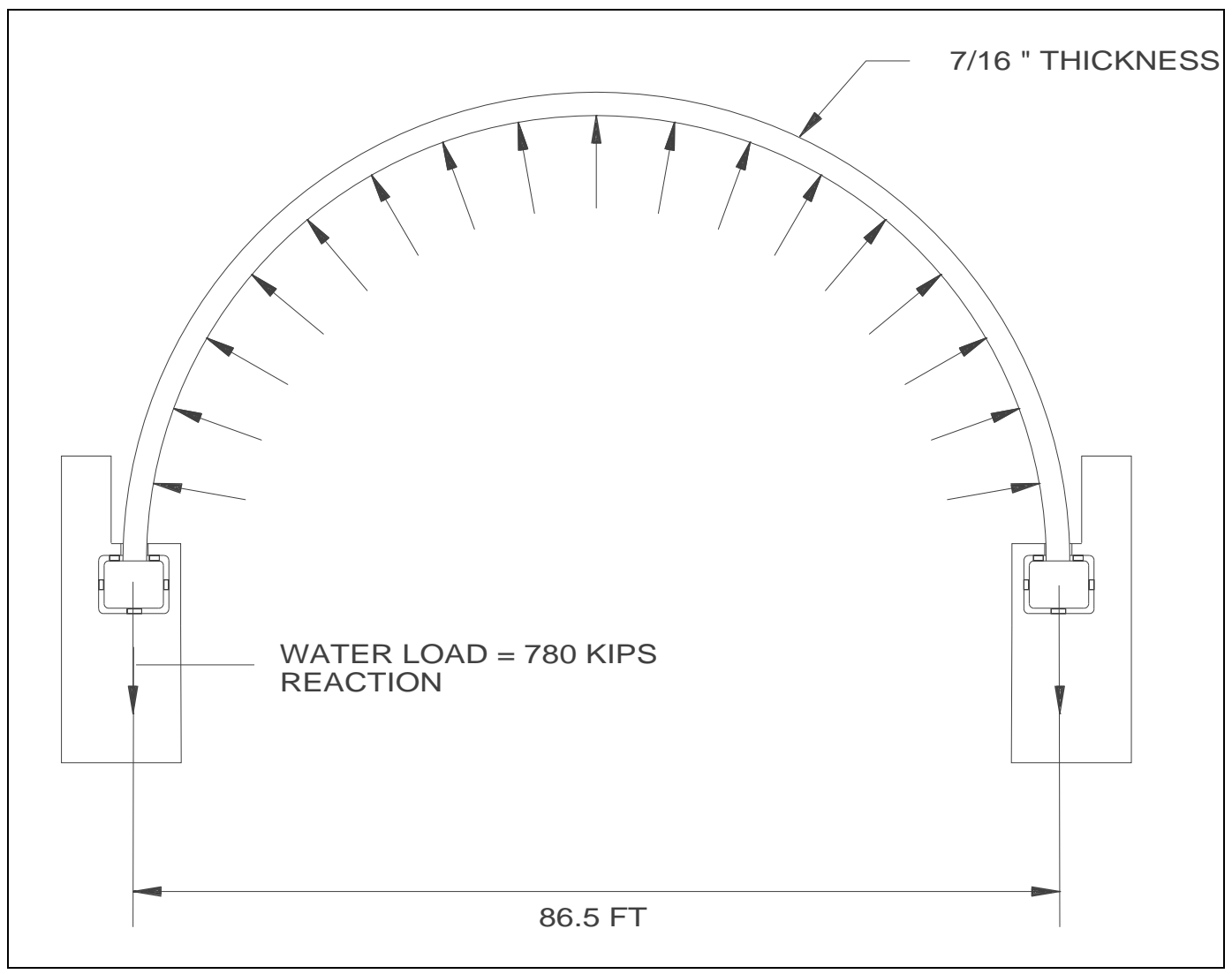

Figure 6. Tension gate concept from New Orleans District.

\begin{tabular}{|c|c|c|}
\hline \multicolumn{3}{|c|}{$\begin{array}{l}\text { Table } 1 \\
\text { Comparative Analysis: Tension Bulkhead/Gate Versus Truss } \\
\text { Bulkhead/Gate }\end{array}$} \\
\hline & Truss Style Bulkhead/Gate & Tension Bulkhead/Gate \\
\hline Span & $86.5 \mathrm{ft}$ & $86.5 \mathrm{ft}$ \\
\hline Height & $77 \mathrm{in.}$ & $77 \mathrm{in.}$ \\
\hline Total horizontal load & 1,560 kips & 1,560 kips \\
\hline Allowable tensile stress & 24,000 psi & $24,000 \mathrm{psi}$ \\
\hline Material & Steel & Steel \\
\hline Weight & $68 \mathrm{kips}$ & 23 kips $^{1}$ \\
\hline
\end{tabular}


PIANC Report: A Permanent International Association of Navigation Congress (PIANC) report (2006) lists two emergency closure systems in use. One is the Blanc-Pain gate in Belgium that protects the 73-m-high shiplift at Strepy and the surrounding countryside from a flood event. The vertical lift gate closes a channel $32.4 \mathrm{~m}$ wide. Another emergency gate is the Goole Caisson in Great Britain, which is a miter gate that prevents the harbor from draining if a breach in the canal wall occurs. Other temporary systems mentioned were a bladder type dam usually constructed of some type of flexible membrane and filled with water to stop the flow, stoplogs, needles, cofferdams, caissons, and air bags. Floating platforms or barges floated into the desired position and sank in a controlled manner to effectively form a dam upstream from the inoperable gate, which could also serve as an emergency closure.

Barkley Dam Bulkhead: An example of an existing emergency bulkhead system used for the Barkley Lock and Dam on the New Cumberland River is shown in Figure 7. The span for this unit is $58 \mathrm{ft}$ from the center to center of the reaction rollers. This type unit could be modified to fit together in sections with quick connect type of connections or maybe even hinged at one or more locations to increase the span length. The intent of the hinge or hinges would be to allow the unit to be transported over the highway on a conventional flatbed trailer.

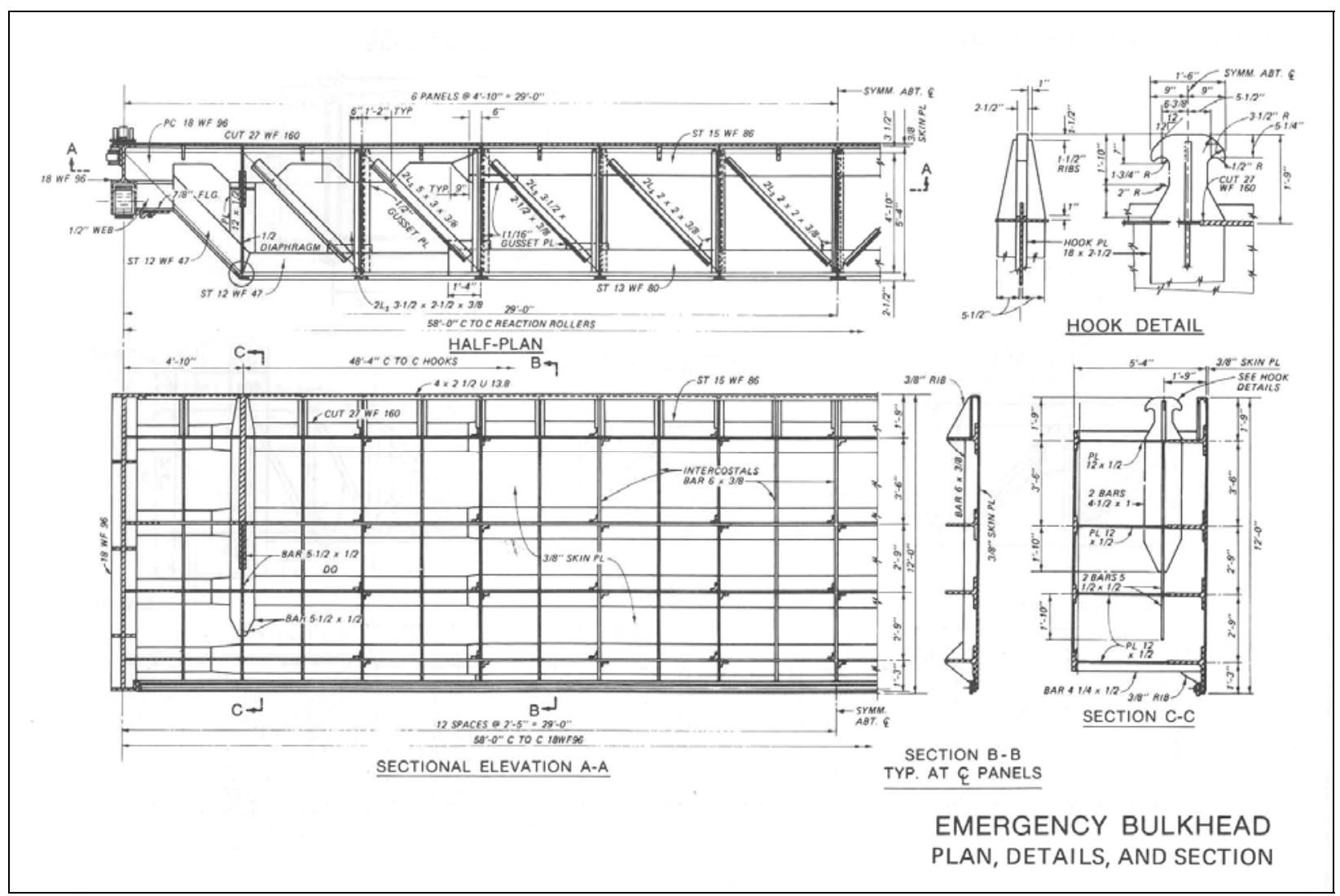

Figure 7. Emergency bulkhead for Barkley spillway gate bay. 


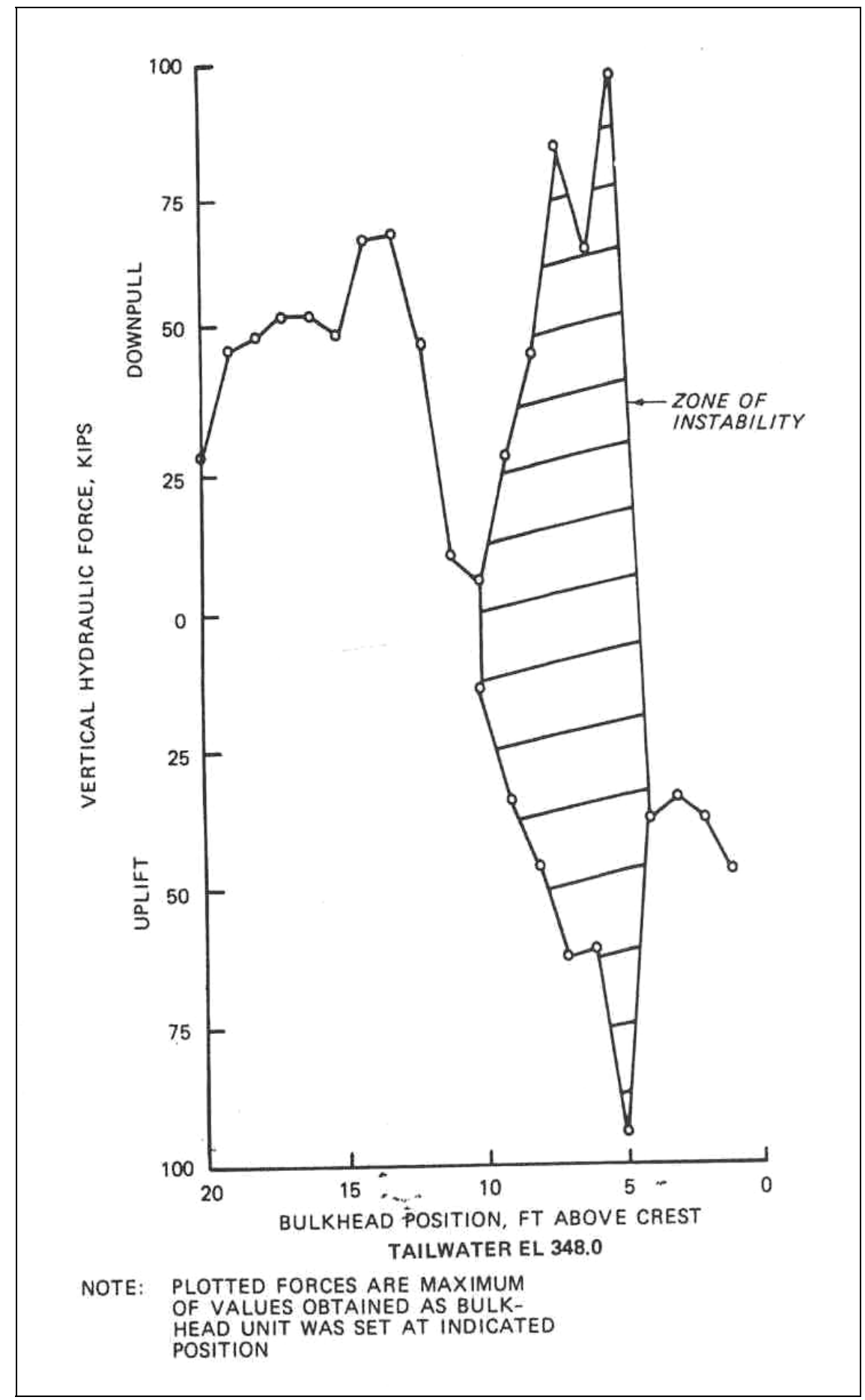

Figure 8. Hydraulic forces determined from model study (Hite and Pickering 1983). 


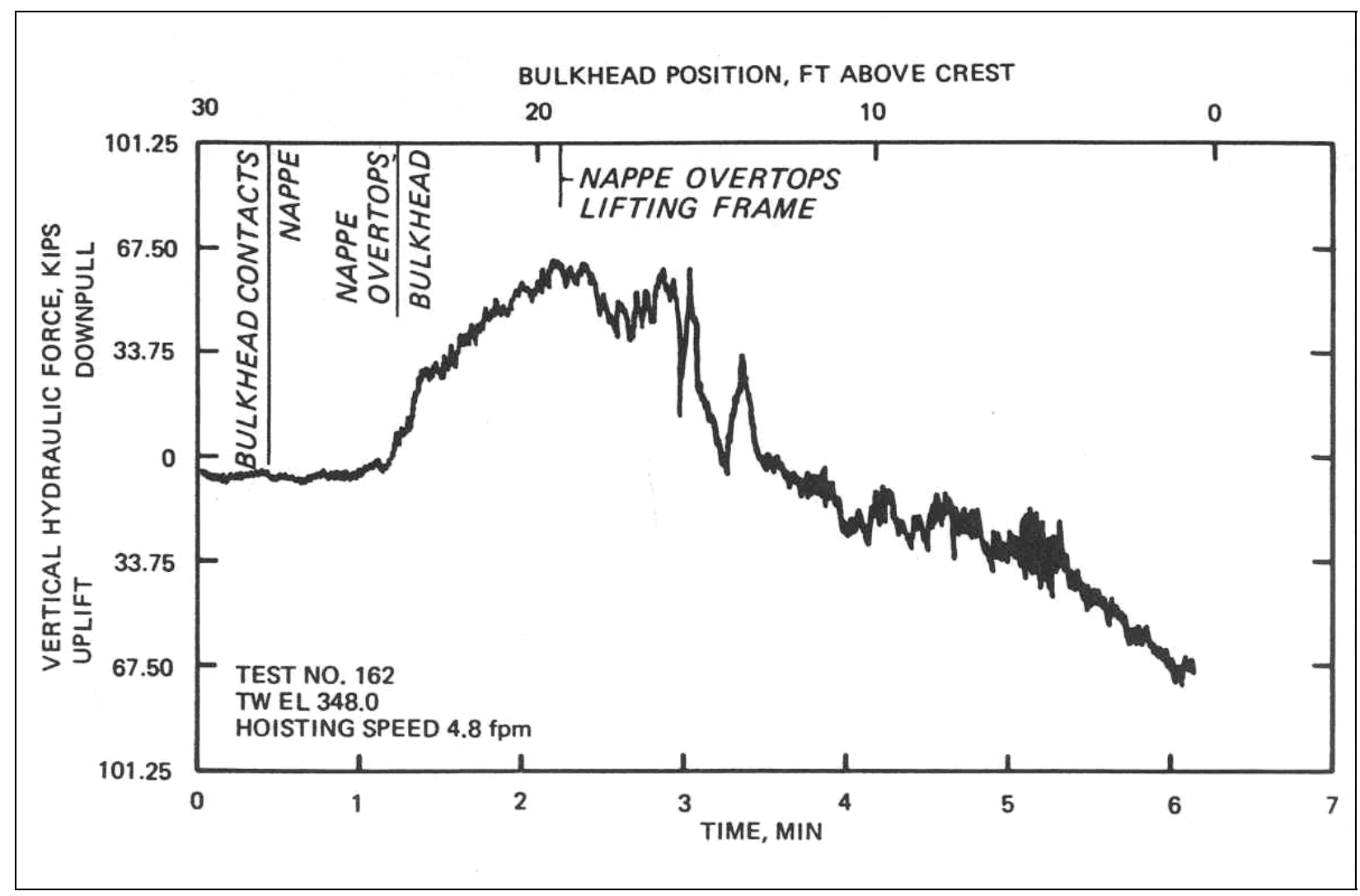

Figure 9. Time-history of hydraulic forces from model study (Hite and Pickering 1983).

WORKSHOP BRAINSTORMING SESSION: A brief brainstorming session was held at the end of the Navigation Lock and Dam Inspection and Emergency Repairs Workshop (Hite 2006) held at the U.S. Army Engineer Research and Development Center, Coastal and Hydraulics Laboratory in April 2006. The purpose was to solicit ideas from the attendees on techniques that could be used for emergency closure systems for projects. The concepts identified by the workshop attendees who participated in this exercise were as follows:

1. Empty barges that can be filled with water or sand and can be sunk.

2. Transportable, stackable bulkheads.

3. Gravity dam.

4. Stockpile rock in accessible area and dump to close off flow.

5. Emergency stoplogs with cradle system - Whitten Lock in the USACE, Mobile District has cradle that will lower five stoplogs.

6. Tension structure.

7. Inflatable dam.

8. Louvered bulkheads.

9. Wicket type structure with hurter box.

10. Shuttered A-frame and top beam system - the McAlpine 600-ft lock had a system like this. 


\section{Floating caisson.}

Some of the concerns expressed for emergency closure systems were as follows:

- Anchor points.

- Should not be too expensive.

- Should be able to deploy quickly.

- Should be able to remove the system quickly.

- Should be readily available.

- Should be transportable.

- Should be adjustable.

With several of these options, anchor points located upstream from the dam were an essential part of the concept. A suggestion was made that possibly barges anchored to land or maybe even on land could be used as anchor points. Many of the participants in this exercise believed that using barges was a practical solution. The salvage companies are used to handling barges and they have indicated they could sink a barge for this type situation. Also many in the group thought it may be worthwhile to go ahead and establish some anchor points upstream in preparation for an emergency situation.

The use of land based bulkheads will require some type of lifting mechanism that may not be able to reach the area of concern. Preparations should be made in advance if this type system is desired to get a lifting mechanism. The equipment at the project might be modified or even the dam and lock may need to be retrofitted with a system to handle the bulkheads.

The concept of using a mesh where some material could be placed upstream from the mesh and the flow would force the material into the mesh is a good way to gradually reduce flow. The material could possibly be rock, steel plates, or even the needle beam type units. The louvered type unit is also a good way to lower something into flowing water and gradually reduce the flow without experiencing excessive hydrodynamic forces.

SUMMARY: After review of available literature, current practices, existing designs, brainstorming, and the requirements for an emergency closure system, several viable alternatives have been identified.

- Loose stone dumped into the flowing water.

- Frames lowered into the flow and filled with a device of some sort to shut off the flow.

- Inflatable bladders.

- A floating platform sunk in a controlled manner.

- Tension gate.

- Bulkhead units with adaptable ends.

There are advantages and disadvantages to each of these alternatives as mentioned in the following paragraphs.

Loose Stone: Dumping loose stone to form a closure requires an available source, and the stone size may become too large depending on the head when the gate fails. Unless the project 
stockpiles this material and keeps the equipment on standby to load and place the stones, this option could probably not be accomplished in time to prevent loss of pool. The material would also have to be removed later after the gate is back in operation, which could result in additional delays to project operation.

Frame Lowered into Flowing Water with Closure Devices: This concept has several different methods that could be used to stop the flow of water. Stoplogs, baskets filled with stone, or some type of needles could all be used to stop the flow of water. Depending on the head at the project, the frame may be large and require specialized equipment to lower and install whatever is selected to stop the flow of water.

Inflatable Bladder: The framework required to hold the bladder in place and the equipment needed to inflate the bladder would be project specific. Placing a 100-ft-long or longer flexible bladder and accompanying framework in flowing water would be difficult, especially for higher heads. A workable anchoring device to hold the bottom of the bladder in place would be the key to this type of closure performing as needed.

Floating Platform: This concept has merit although the floating platform would need to be stored and available at the project and therefore would not be accessible for multiple project use. Also, more than one platform may be needed depending on the gate bay size compared to the lock gate. A customized working platform would more than likely be needed to successfully sink the floating platform in the desired manner.

Tension Gate: The major advantage of the tension gate is the reduction in weight compared to a more conventional bulkhead design. However, this may not be an advantage as an emergency closure since the unit has to be lowered in flowing water. The unit would be difficult to make adaptable in width.

Segmental Bulkhead Units: This type of emergency closure system is considered the most functional for an inland navigation project. It has the following attributes:

- Adaptable for 110 -ft- or 100 -ft-wide lock chamber or dam gates (need method to adjust length and provide necessary bearing).

- Can be transported over the highway (flatbed trailer).

- Should be segmental (put together in sections).

- Does not require specialized equipment to deploy.

The loss of control due to failure of a spillway gate is much more probable than a lock gate. Both lock gates would have to fail for uncontrolled flow to occur through the lock. The design for an emergency closure system should focus on spillway gate bays but have the capability to work in the approach to the lock chamber.

RECOMMENDATIONS: This review into emergency closure systems revealed there is a definite need to pursue an emergency closure design for the Corps' inland navigation projects. Recent accidents and gate operating problems have resulted in significant economic impacts. Salvage operations also have to be considered in addition to emergency closure systems. Ideally, equipment used for the salvage operation might also be used to help deploy the emergency 
closure system. The emergency closure system should be adaptable for either a lock gate or a spillway gate. Segmental bulkheads that can be adjusted in length and are easily transported are recommended for this application. A design team composed of structural, mechanical, hydraulic, construction, and operation and maintenance disciplines could develop a prototype design. The performance of the design should be evaluated for both lock gate and spillway gate applications using existing numerical models and later at a site representative of a typical inland navigation project. The design may need slight modifications during the evaluation. A proposal will be developed and submitted to the Navigation Systems Research Program for ranking by the Inland Navigation Focus Area review members.

ADDITIONAL INFORMATION: This CHETN is a product of the Program Management Work Unit of the Navigation Systems Research Program (Nav Sys) being conducted at the U.S. Army Engineer Research and Development Center, Coastal and Hydraulics Laboratory. Questions about this technical note can be addressed to Dr. John E. Hite, Jr. (Voice: 601-634-2402, Fax: 601-634-2645, e-mail: John.E.Hite@usace.army.mil). For information about the Navigation Systems Research Program (Nav Sys), contact the Nav Sys Program Manager, James E. Clausner at 601-634-2009, e-mail: James.E.Clausner@usace.army.mil. This document should be cited as:

Hite, J. E., Jr. 2008. Concept design for emergency closure system for inland navigation structures. ERDC/CHL CHETN-IV-70. Vicksburg, MS: U.S. Army Engineer Research and Development Center. http://chl.erdc.usace.army.mil/chetn

\section{REFERENCES}

Headquarters, U.S. Army Corps of Engineers. 1994. Engineering and design - lock gates and operating equipment. EM 1110-2-2703, Washington, DC: Headquarters, U.S. Army Corps of Engineers.

1995a. Planning and design of navigation locks. EM 1110-2-2602, Washington, DC: Headquarters, U.S. Army Corps of Engineers.

1995b. Hydraulic design of navigation locks. EM 1110-2-1604, Washington, DC: Headquarters, U.S. Army Corps of Engineers.

Hite, J. E., Jr. and G. A. Pickering. 1983. Barkley Dam Spillway Tainter Gate and Emergency Bulkheads Cumberland River, Kentucky. Technical Report HL-83-12. Vicksburg, MS: U.S. Army Engineer Waterways Experiment Station.

Hite, J. E., Jr., J. E. Clausner, and D. N. McComas. 2006. Navigation lock and dam inspection and emergency repairs workshop summary. ERDC/CHL SR-06-02, Vicksburg, MS: U.S. Army Engineer Research and Development Center.

PIANC InCom Working Group 26. 2006. Movable weirs and storm surge barriers. Brussels Belgium: Permanent International Association of Navigation Congress.

Waterways Journal. Broken valve plagues McAlpine Lock. 114 (35): 6. St. Louis, MO.

NOTE: The contents of this technical note are not to be used for advertising, publication, or promotional purposes. Citation of trade names does not constitute an official endorsement or approval of the use of such products. 